\section{A Whole-plant, Open, Gas-exchange System for Measuring Net Photosynthesis of Potted Woody Plants}

\author{
D.P. Miller' ${ }^{1}$, G.S. Howell, and J.A. Flore \\ Department of Horticulture, Michigan State University, East Lansing, \\ MI 48824
}

Additional index words. photosynthesis, apparatus

\begin{abstract}
Chambers were constructed to measure gas exchange of entire potted grapevines (Vitis vinifera L.). The plant enclosures were constructed from Mylar film, which is nearly transparent to photosynthetically active radiation. Maintaining a slight, positive, internal pressure allowed the Mylar chambers to inflate like balloons and required no other means of support. The whole-plant, gas-exchange chamber design and construction were simple and inexpensive. They were assembled easily, equilibrated quickly, and did not require cooling. They allowed for the measurement of many plants in a relatively short period. This system would enable the researcher to make replicated comparisons of treatment influences on whole-plant $\mathrm{CO}_{2}$ assimilation throughout the growing season. While $\mathrm{CO}_{2}$ measurement was the focus of this project, it would be possible to measure whole-plant transpiration with this system.
\end{abstract}

Measurement of leaf gas exchange is an important technique used to estimate net photosynthesis (Pn). Individual-leaf photosynthetic determinations, however, have limitations when used to estimate whole-plant $\mathrm{CO}_{2}$ exchange. Leaf Pn can be highly variable due to differences in leaf age (Poni et al., 1994a), chlorophyll content (Candolfi-Vasconcellos and Koblet, 1991), angle of incident radiation (Flore and Lakso, 1989), leaf shading (Flore, 1994), respiration of vegetative and reproductive tissues (Corelli-Grappadelli and Manganini, 1993), or biotic or abiotic stress. In addition, variability may result from differences within and between plants due to crop load, the proximity of carbohydrate sinks, and other source-sink relationships (Edson, 1991). Consequently, although individual leaf measurements estimate the relative carbon uptake per unit leaf area, it is problematic to extrapolate to whole-plant assimilation from these values.

An accurate assessment of the total, net carbon uptake of whole plants is essential if production per unit land area is to be maximized. One approach is to place the entire plant in a whole-plant, gas-exchange system (Katerji et al., 1994). Heinecke and Childers (1937) first devised a whole-tree, gas-exchange

\footnotetext{
Received for publication 16 Nov. 1995. Accepted for publication 25 May 1996. We thank A. Lakso for helpful suggestions and M. Cameron for her assistance with drawings. The cost of publishing this paper was defrayed in part by the payment of page charges. Under postal regulations, this paper therefore must be hereby marked advertisement solely to indicate this fact.

${ }^{1}$ To whom reprint requests should be addressed.
}

system for an apple tree in 1935. Since then, modern materials and portable gas-analysis equipment have allowed for construction of chambers that are easier to use (Long and Hallgren, 1985). Recently, the performance of polyethylene chambers, used continuously in the field on apple trees (Corelli-Grappadelli and Manganini, 1993) and grapevines (Katerji et al., 1994), was reported. Those chambers were inexpensive, easy to build, and did not require cooling because they did not trap significant quantities of infrared radiation. High flow rates ensured rapid exchange of air within the chamber. Additionally, polyethyleneblocks very little incident radiation in the photosynthetically active range, allowing saturating light conditions under full sun. The chambers described, however, were not moved easily from plant to plant, so the number of treatments or replications that could be monitored was limited.

The goal of this study was to design, build, and test an open gas-exchange system for whole potted plants. We wanted the following attributes: 1 ) inexpensive; 2 ) easily constructed from off-the-shelf items; 3 ) low volume relative to plant size so high airflow rates could be used; 4) no need for cooling; 5) rapid equilibration for higher throughput of plant materials; and 6) easily assembled and disassembled, making it somewhat portable. We also wanted chamber conditions to be near ambient so leaf temperature and gas environment would not affect photosynthetic processes.

\section{Materials and Methods}

Chamber construction. Work by other researchers (Corelli-Grappadelli and Manganini, 1993) suggested that the easiest and least expensive approach to achieve our goals was to construct open system chambers that essentially were balloons made of Mylar film (poly- ethylene terephthalate, polyvinylidene chloride coated; DuPont, Wilmington, Del.). If a slight positive pressure exists in such a chamber, no other means of support is necessary, and any small leaks in the system flow out of the chamber so that there is no affect on $\Delta \mathrm{CO}_{2}$. A benefit of an open system is that small chamber leaks are acceptable.

The plant chambers were constructed around a wood base (Fig. 1 A and B) $43.0 \mathrm{~cm}$ long and $39.5 \mathrm{~cm}$ wide. This base was cut in an obovate shape from 1.6-cm-thick plywood. Holes were cut to accommodate the plant stem (a grapevine) (3.8 $\mathrm{cm}$ in diameter) and the air inlet pipe $(5.7 \mathrm{~cm}$ in diameter). The base was then cut in half through the stem opening so that it could be moved on and off vines (Fig. 1B). Two chest-latches held the base together during operation. A sleeve of sealed-cell foam was placed around the vine stem. The foam was slightly larger in diameter than the opening for the vine stem, enabling the chamber base to compress the sleeve and form a relatively tight seal around the stem. This design separated the vine from the potting soil to eliminate the effects of soil and root respiration on $\mathrm{CO}_{2}$ determinations. To maximize the number of plants that could be measured in a given interval, two chambers were employed, one in which a plant could equilibrate while the other was being measured.

The actual chambers consisted of Mylar M-30 film rolled into a cylinder of a diameter slightly larger than that of the wooden bases. This cylinder was sealed with clear box tape along the seam. An outlet port of 5.7-cm inside diameter (i.d.) was constructed. Polyvinylchloride (PVC) pipe was attached using tape and rubber bands to draw the distal end of the chamber together, forming a roughly hemispherical top above a cylindrical chamber. The chambers were attached to the base using an elastic band fitted into a groove cut around the periphery of the base (Fig. 1B, inset).

Light transmission of the Mylar film in the photosynthetically active range of radiation is $\approx 90 \%$ (similar to polyethylene) (R. Richmond, personal communication), and permeability to $\mathrm{CO}_{2}, \mathrm{H}_{2} \mathrm{O}$, and $\mathrm{O}_{2}$ is low relative to other films (Pauly, 1989). In addition, high flow rates minimized the effects of gaseous losses or gains that might occur through the film, thereby reducing variation arising from this source.

The air-supply system consisted of a small, squirrel-cage fan with a maximum, unrestricted output of $4500 \mathrm{~L} \cdot \mathrm{min}^{-1}$ (model IC982B; Dayton Inc., Dayton, Ohio). This fan was attached to a 10.2-cm-i.d. PVC pipe "T" to allow distribution of air to the two chambers. Each air stream then flowed through a 1.2-m length of 10.2-cm-i.d. PVC pipe whose diameter was reduced to $5.1 \mathrm{~cm}$ i.d. before the inlet into the chambers. Airflow was regulated by controlling fan speed.

Airflow and temperature were measured using a thermal anemometer (model 3700000; Cole-Parmer, Chicago). Airflow was measured midway on the inlet pipe by taking eight readings of equal cross-sectional area and then averaging these (R. Beaudry, personal com- 

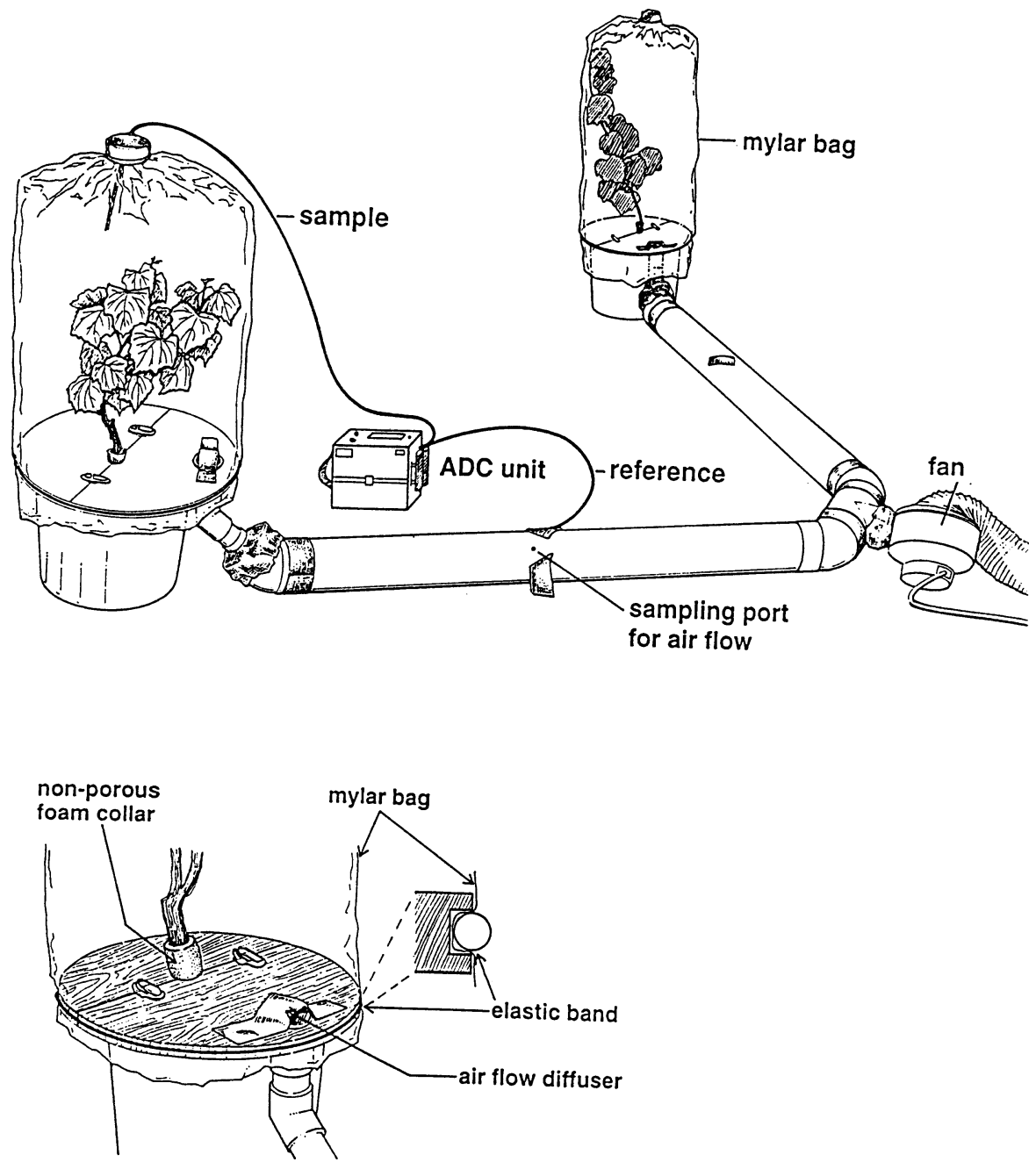

Fig. 1. (A) Whole-plant, gas-exchange system showing both chambers, air supply system, location of airflow measurement ports, and infrared gas analyzer hookup. (B) Detail of chamber base showing sealedcell foam collar sealing the trunk, latches for fastening chamber halves, air diffuser, and attachment of Mylar balloon with elastic band. Inset shows detail of elastic band positioning attachment.

munication). Volume of air was calculated from linear flow data by the equation:

$$
V=\frac{\pi r^{2} l}{1000}
$$

where: $V=$ volume of air in $\mathrm{L} \cdot \mathrm{s}^{-1}, r=$ the inside radius of the air supply line in $\mathrm{cm}$, and $l=$ the linear flow rate of air in $\mathrm{cm} \cdot \mathrm{s}^{-1}$.

Air volume was calculated and then corrected using the chamber calibration curve described below. Laminar flow from the chamber inlet to its outlet was prevented by placing a piece of tape, as an air diffuser, loosely over the chamber inlet. Mixing was verified by introducing smoke into a chamber containing a vine.

Leaf temperature was measured simultaneously on two vines, one outside and the other inside a chamber, over a range of chamber airflow rates. Measurement was by means of a copper-constantan "needle" thermocouple probe inserted into a leaf in full sun on each vine and connected to a handheld microprocessor thermometer (model HH23; Omega Engineering, Stamford, Conn.). Leaf temperatures inside the chamber were 1 to $2{ }^{\circ} \mathrm{C}$ higher than outside using airflow rates similar to those used for Pn determination. At very low flow rates, leaf temperature inside a chamber increased 5 to $6{ }^{\circ} \mathrm{C}$ above that of leaves under ambient conditions, indicating the need to use the highest flow rates that allow accurate determination of $\Delta \mathrm{CO}_{2}\left(\Delta \mathrm{CO}_{2}\right.$ readings in the 15 to $35 \mu \mathrm{L} \cdot \mathrm{L}^{-1}$ range).

Measurement of $\Delta \mathrm{CO}_{2}$ was accomplished using a portable infrared gas analyzer (IRGA) (ADC LCA-2; Analytical Development Co., Hoddesdon, U.K.). A reference sample was obtained from an inlet pipe, and the sample $\mathrm{CO}_{2}$ measurement was obtained from a chamber outlet. The $\Delta \mathrm{CO}_{2}$ concentrations were determined only after vines had equilibrated in the chambers for 5 min after the IRGA readings had stabilized.

Whole-vine $\mathrm{CO}_{2}$ assimilation $(\mu \mathrm{mol}$ $\left.\mathrm{CO}_{2} \cdot \mathrm{vine}^{-1} \cdot \mathrm{s}^{-1}\right)$ was calculated as follows:

$$
\operatorname{Pn}\left(\mu \mathrm{mol} \cdot \text { vine } e^{-1} \cdot \mathrm{s}^{-1}\right)=\frac{\left(\Delta C \mathrm{O}_{2}\right) \mu L \cdot L^{-1} \times(\text { flow }) L \cdot \mathrm{min}^{-1}}{29.2 \mu L \cdot \mu \mathrm{mol} l^{-1} \times 60 s \cdot \mathrm{min}^{-1}}
$$

where: $\Delta \mathrm{CO}_{2}=\left[\mathrm{CO}_{2}\right]_{\text {in }}-\left[\mathrm{CO}_{2}\right]_{\text {out }}$.
Flow was calculated from anemometer readings. To convert $\mathrm{CO}_{2}$ volume to $\mathrm{CO}_{2}$ concentration, $29.2 \mu \mathrm{L} \cdot \mu \mathrm{mol}^{-1}$ was used and was calculated at standard temperature $\left(20^{\circ} \mathrm{C}\right)$. At the higher temperatures often encountered in the chambers $\left(26\right.$ to $\left.36^{\circ} \mathrm{C}\right), 29.2 \mu \mathrm{L}$ was $<1$ $\mu \mathrm{mol}$, which introduces an error into the calculation of $\mathrm{CO}_{2}$ concentration. However, the error was $\leq 0.5 \%$ over the range of temperatures encountered.

Chamber calibration. The reduction of inlet-pipe diameter at the chamber caused turbulence in the pipe segment where airflow was measured, leading to high thermal anemometer readings. To correct for this problem, airflow into an empty chamber was calculated by measuring the dilution of a stream of $\mathrm{CO}_{2}$ of known concentration and flow rate. The values obtained over a range of chamber airflow rates were then regressed on values obtained using the thermal anemometer at the same flow rates. The regression equation $(\mathrm{y}=0.51 \mathrm{x}$ $-0.10)\left(r^{2}=0.99\right)$ was used to correct the flow calculated from the anemometer readings.

Chamber use for Pn measurement. Two grapevines were placed in the chambers, and the Mylar balloons were sealed over them. Airflow was reduced to 80 to $250 \mathrm{~L} \cdot \mathrm{min}^{-1}$, depending on vine leaf area. After airflow and chamber pressure had stabilized, airflow was recorded. $\Delta \mathrm{CO}_{2}$ was measured when the IRGA readings stabilized. The IRGA was then moved to the second chamber, which at that point was in dynamic equilibrium, and the measurements were repeated.

Two vines required 15 to $20 \mathrm{~min}$, thus 12 readings were possible in $1.5 \mathrm{~h}$. Data were collected on four replicate vines.

Single-leaf Pn measurements. Pn of single leaves was measured at the same physiological growth stages as were whole vines. Data were collected on a recently fully expanded leaf using an ADC LCA-2 portable, open gasexchange system equipped with a Parkinson broadleaf chamber and an air supply unit (Analytical Development Co.). These data were used to calculate whole-vine Pn. It was then possible to compare data for the whole vines with those calculated.

Plant material. The plant materials used were 1-year-old 'Chambourcin' grapevines grafted to 5-C rootstock and potted in 19-L pots using $45 \%$ sand, $45 \%$ loam, and $10 \%$ peat by volume. The vines were watered regularly and fertilized monthly. Vines were divided into four blocks by their fresh weight before planting and trained to three shoots per individual vine.

The relationship between leaf area and shoot length was determined previously to be $\mathrm{y}=15.69 \mathrm{x}-27.83\left(r^{2}=0.88\right)$ (Miller et al., 1996). Shoot length measurements were then used to estimate vine leaf area at each date of measurement. Net $\mathrm{CO}_{2}$ assimilation was determined at three times during the growing season as shown by growing degree day (GDD; base $10^{\circ} \mathrm{C}$ ) accumulation. The vines used had no fruit, but several indicator vines not in the study were used to mark important phenological events. Measurements of Pn were made at prebloom (400 GDD), when berries were 5 

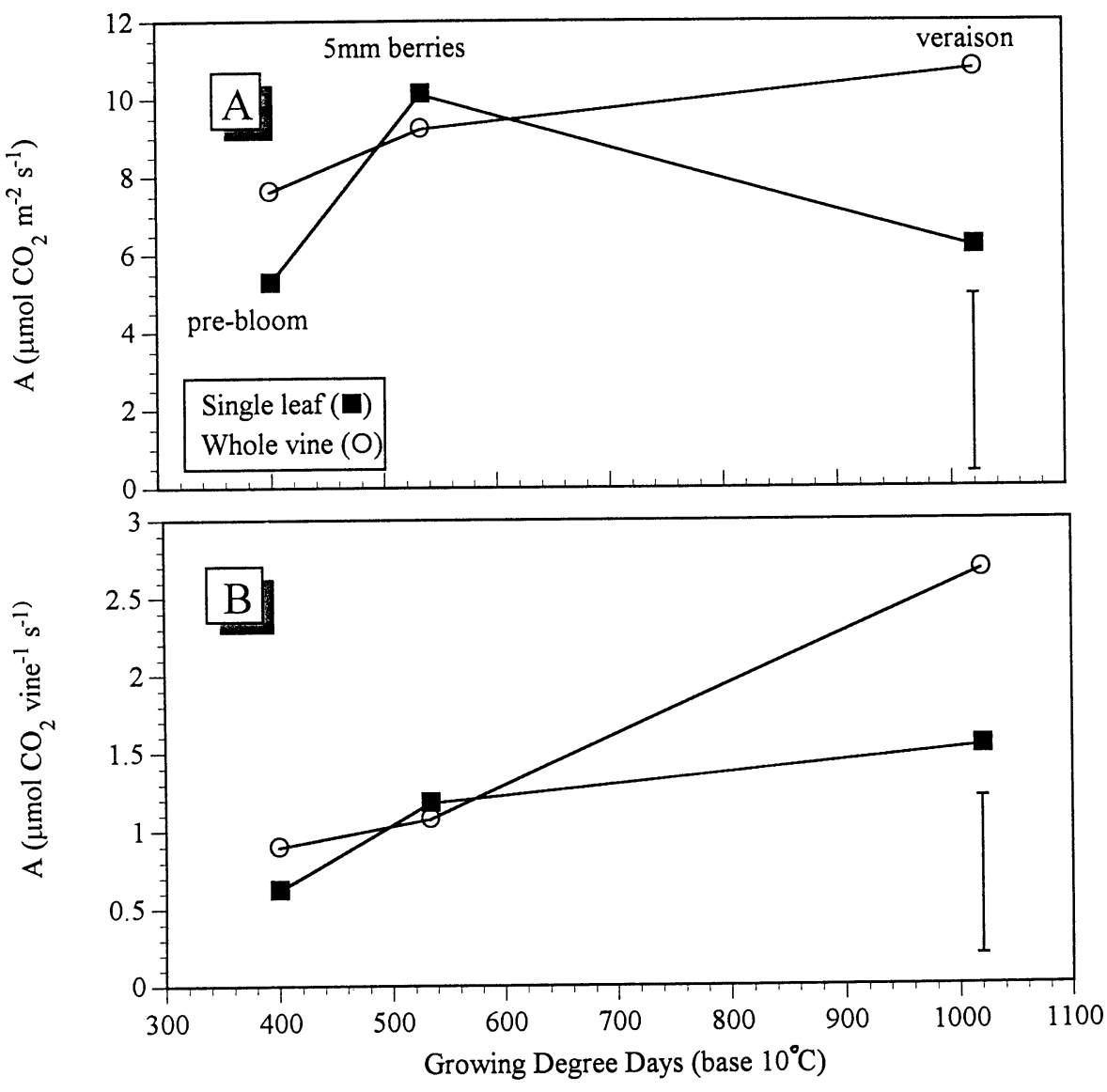

Fig. 2. (A) Carbon dioxide assimilation of 'Chambourcin' grapevines. Measurement using a Parkinson broadleaf chamber $(\mathbf{\square})$ or whole-plant chambers $(\bigcirc)$. (A) Carbon dioxide assimilation per unit leaf area $\left(\mu \mathrm{mol} \cdot \mathrm{m}^{-2} \cdot \mathrm{s}^{-1}\right)$ and $(\mathbf{B}) \mathrm{CO}_{2}$ assimilation per vine $\left(\mu \mathrm{mol} \cdot \mathrm{s}^{-1}\right)$. Bars represent LSD at $P \leq 0.05$.

$\mathrm{mm}$ in diameter (515 GDD), and at veraison (30\% of berries colored) at 1010 GDD.

\section{Results and Discussion}

Actual airflow rates were calculated using the calibration curve. The values were about one-half the values measured with the thermal anemometer, demonstrating the need to calibrate the chambers for accurate and precise data.

Carbon dioxide assimilation per unit leaf area was measured on an individual leaf or was calculated from whole-vine measurements (Fig. 2A). Net assimilation determined using a single-leaf measurement was less than the calculated assimilation rate per unit leaf area as determined from the whole-vine at veraison only.

Net $\mathrm{CO}_{2}$ assimilation per vine was either measured for entire vines or calculated from single-leaf measurements (Fig. 2B). Wholevine Pn measured using entire vines was higher than that calculated from single leaves at veraison only. Using single-leaf Pn measurements to calculate whole-vine Pn (in a pottedvine system with no fruit present) gave results that agreed with whole-vine measurements early in the season. However, as the season progressed and the canopy became more com- plex due to increasing leaf area $\left(\approx 3000 \mathrm{~cm}^{2}\right.$ at harvest), estimates of whole-vine Pn using a recently fully expanded leaf were inaccurate.

Use of whole-plant, open, gas-exchange systems measures Pn of potted plants and integrates respiration and other factors affecting Pn to give an accurate measurement of whole-plant carbon assimilation.

\section{Literature Cited}

Candolfi-Vasconcelos, M.C. and W. Koblet. 1991. Influence of partial defoliation on gas exchange parameters and chlorophyll content of field grown grapevines-Mechanisms and limitations of the compensation capacity. Vitis 30:129141.

Corelli-Grappadelli, L. and E. Magnanini. 1993. A whole-tree system for gas exchange studies. HortScience 28:41-45.

Edson, C.E. 1991. Influence of crop level on single leaf and whole vine photosynthesis and dry matter partitioning in Seyval grapevines (Vitis sp.) PhD Diss., Michigan State Univ. (Diss. Abstr. 91-34113)

Flore, J.A. 1994. Stone fruit, p. 233-270. In: B. Schaffer and P.C. Andersen (eds.). Environmental physiology of fruit crops. vol. I: Temperate crops. CRC Press, Boca Raton, Fla.

Flore, J.A. and A.N. Lakso. 1989. Environmental and physiological regulation of photosynthesis in fruit crops. Hort. Rev. 11:111-146.

Heinecke, A.J. and N.F. Childers. 1937. The daily rate of photosynthesis during the growing season of 1935, of a young apple tree of bearing age. Cornell Univ. Agr. Expt. Sta. Mem. 201.

Katerji, N., F.A. Daudet, A. Carbonneau, and N. Ollat. 1994. Photosynthesis and transpiration studies with traditionally and lyre-trained vines. Vitis 33:197-203.

Long, S.P. and J.E. Hallgren. 1985. Measurement of $\mathrm{CO}_{2}$ assimilation by plants in the field and in the laboratory, p. 62-94. In: J. Coombs, D.O. Hall, S.P. Long, and J.M.O. Scurlock (eds.). Techniques in bioproductivity and photosynthesis. Pergamon Press, Oxford, U.K.

Miller, D.P., G.S. Howell, and J.A. Flore. 1996. Effect of varying numbers of shoots on grapevines: I. Canopy development and morphology. Amer. J. Enol. Viticult. 46:(In press.)

Pauly, S. 1989. Permeability and diffusion data, p. 435-439. In: J. Brandrup and E.H. Immergut (eds.). Polymer handbook. 3rd ed. Wiley, New York.

Poni, S., C. Intrieri, and O. Silvestroni. 1994a. Interactions of leaf age, fruiting, and exogenous cytokinins in Sangiovese grapevines under nonirrigated conditions I. Gas exchange. Amer. J. Enol. Viticult. 45:71-78. 